\title{
A COLOCAÇÃO PRONOMINAL EM COMPLEXOS VERBAIS NA ESCRITA DE JORNAIS BRASILEIROS E EUROPEUS NOS SÉCULOS XIX E XX
}

\author{
CLITIC ORDER IN COMPLEX VERBAL FORMS IN BRAZILIAN AND EUROPEAN \\ JOURNALISTIC TEXTS FROM THE $19^{T H}$ AND $20^{T H}$ CENTURIES
}

Carla da Silva Nunes

Doutoranda da Universidade Federal do Rio de Janeiro carla.s.nunes@gmail.com

\author{
Silvia Rodrigues Vieira \\ Professora da Universidade Federal do Rio de Janeiro/FAPERJ \\ silviavieira@hotmail.com
}

RESUMO: Com base em uma análise variacionista diacrônica, de orientação laboviana, a presente pesquisa busca descrever o padrão da colocação pronominal em estruturas com complexos verbais em jornais produzidos no Brasil e em Portugal nos séculos XIX e XX. Consideraram-se as quatro variantes a seguir para a análise do fenômeno: cl V1 V2 (se deve fazer); V1-cl V2 (deve-se fazer); V1 cl V2 (deve se fazer); e V1 V2-cl (deve fazer-se), com base em dados coletados em anúncios, editoriais e notícias, sendo a maioria do corpus do Projeto Varport. Acredita-se que a variante considerada inovadora (V1 cl V2) não seria produzida pelos europeus nos dois séculos em questão, sendo realizada apenas na escrita brasileira, significativamente no século XX. Os resultados apontam que, no século XIX, o Brasil tende a seguir, com alguma variação, o padrão lusitano da colocação pronominal, que era o da próclise a $\mathrm{V} 1$, diante de elementos proclisadores em contextos não iniciais, e da ênclise a V1/V2 na ausência desses possíveis proclisadores. A partir do século $\mathrm{XX}$, as produções do Brasil apresentam, de forma crescente, dados de próclise a V2, o que não ocorre em Portugal, que tende a distribuir equilibradamente as variantes pré e pós complexo verbal, sempre vinculadas às restrições estruturais, como as referentes aos tipos de proclisador, de clítico e de complexo verbal. Os resultados do fim do século XX sugerem que a escrita brasileira passa a incorporar, cada vez mais, as mudanças linguísticas já implementadas na fala vernacular.

PALAVRAS-CHAVE: Clíticos pronominais; Variação; Mudança linguística.

ABSTRACT: Based on a diachronic variationist analysis of Labovian orientation, this work aims to describe the patterns of pronominal order in structures with verbal complexes in newspapers written in Brazil and in Portugal in the $19^{\text {th }}$ and $20^{\text {th }}$ centuries. The following four variants have been considered for the phenomenon under analysis: cl V1 V2 (se deve fazer); V1-cl V2 (deve-se fazer); V1 cl V2 (deve se fazer); V1 V2-cl (deve fazer-se), based on data collected from advertisements, editorials and news, the majority from the VARPORT Project data. It is believed that the innovative variant (V1 cl V2) has not been produced by Europeans in the $19^{\text {th }}$ and $20^{\text {th }}$ centuries, but only in Brazilian texts, mainly in the $20^{\text {th }}$ century. Results show that, in the $19^{\text {th }}$ century, Brazil tends to follow the Portuguese pattern of pronominal collocation, which consists of locating the pronoun before V1 and following attractive particles, considering non-initial contexts, and of locating the pronoun after V1/V2 whenever an attractor is missing. From the $20^{\text {th }}$ century on, Brazilian productions seldom present proclitic pronouns to V2, differently from European texts, which tend to exhibit "pre and post" verbal complex variants in equilibrium, but always associated to structural constraints, according to types of attractive particles, clitic pronouns and verbal complexes. Results from the end of the $21^{\text {th }}$ century suggest that Brazilian texts tend to incorporate implemented linguistic changes in vernacular language.

KEYWORDS: Pronominal clitics; Variation; Linguistic change. 


\section{INTRODUÇ̃̃OO}

O presente trabalho, de cunho variacionista, tem como finalidade descrever o padrão de ordem dos clíticos pronominais na escrita brasileira e europeia dos séculos XIX e XX, considerando especificamente o contexto de sentenças com complexos verbais. Para a análise, coletaram-se dados de jornais brasileiros e europeus nos gêneros textuais anúncios, editoriais e notícias.

Embora muitos estudos tenham desenvolvido a análise de dados da colocação pronominal na Língua Portuguesa - Pereira (1981); Pagotto (1992); Martins (1994); Cyrino (1996); Lobo (1992, 2001); Vieira (2002); Schei (2003); Galves, Brito e Paixão de Souza (2005); Carneiro (2005); Morito Machado (2006); Nunes (2009); Martins, M. (2009); Cassimiro (2010); Rodrigues Coelho (2011); Vieira, F. (2011); Correa (2012) -, são em número menor as produções que apresentam apreciação detalhada dos dados de complexos verbais, estruturas por si só de "complexa" delimitação. Nesta pesquisa, levam-se em conta as diversas construções com dois ou mais verbos com algum grau de dependência sintático-semântica, em relação às quais se pode observar a posição variável do pronome átono. Apesar de ter havido substanciais avanços no tratamento do fenômeno, acredita-se que ainda há muito por fazer no que se refere ao detalhamento na abordagem sincrônica e diacrônica da ordem em tais construções nas diversas variedades do Português.

Com base nos resultados do trabalho de Nunes (2009), descreve-se, neste artigo, a produtividade das variantes face ao período em que foram publicados os textos e à variedade em questão. Não se pretende, portanto, detalhar, nos limites deste trabalho, as restrições estruturais do fenômeno, que são, sem dúvida, de fundamental importância. Antes, prioriza-se a evolução geral do panorama histórico da ordem dos clíticos em complexos verbais em dados da escrita jornalística brasileira e portuguesa, considerando-se a produtividade das estruturas a seguir: cl V1 V2 (se deve fazer); V1-cl V2 (deve-se fazer); V1 cl V2 (deve se fazer); e V1 V2$\mathrm{cl}\left(\right.$ deve fazer-se) ${ }^{1}$.

Antes do mais, é preciso esclarecer que se tomou por critério, para a configuração da regra variável, tão-somente a possibilidade de as estruturas constituírem formas alternantes. Em outras palavras, assume-se, aqui, que, em termos variacionistas, é possível ocorrer a alternância entre as quatro formas, sem determinar a priori contextos invariantes, o que seria incompatível com o quadro teórico assumido. Por hipótese, espera-se que (i) os contextos morfossintáticos possam revelar fortes condicionamentos em favorecimento a uma das formas alternantes e (ii) os resultados sejam diferentes em cada variedade do Português, o que faria reconfigurar a regra variável, se necessário.

Postula-se, por hipótese, que as fases iniciais da escrita brasileira do século XIX apresentariam dados com maior produtividade das variantes pré e pós-complexo verbal. Por outro lado, a variante interna ao complexo verbal, especialmente a inovadora próclise a V2, apresentaria um aumento significativo com o passar das fases até o final do século XX. Essa variante, por força do modelo de norma adotado em fins do século XIX, seria evitada nesse

\footnotetext{
${ }^{1}$ Sabe-se que o controle da presença do hífen como indicadora da ênclise a V1 e a consideração da ausência do hífen como sinalizadora da próclise a V2, embora adotada em diversos estudos, não é consensual. Martins (2009), por exemplo, considera inicialmente os dados sem hífen ambíguos, embora posteriormente também os retome como casos de próclise a V2. Para o debate sobre questões metodológicas concernentes ao tratamento da colocação pronominal em complexos verbais, Vieira (2012) apresenta amplo levantamento dos trabalhos sobre o tema. Em linhas gerais, saliente-se, aqui, que a categorização das variantes em nada se relaciona à direção fonético-fonológica da cliticização, que, como demonstra Klavans (1989), se refere exclusivamente à fala e é independente do parâmetro da ligação sintática.
} 
período, o que aproximaria o comportamento dos dados europeus e brasileiros. Quanto à escrita europeia, acredita-se que, além de não registrar a variante V1 cl V2, apresentaria preferencialmente as variantes enclíticas em contextos sem elemento proclisador e a variante proclítica a V1 mediante elemento proclisador; ademais, não haveria na escrita portuguesa, em relação ao conjunto das variantes, mudanças relevantes no traçado histórico, sendo o condicionamento da ordem dos clíticos acima de tudo morfossintático.

\section{ASPECTOS METODOLÓGICOS}

Diversos procedimentos foram adotados para o desenvolvimento da pesquisa sociolinguística, de orientação laboviana (WEINREICH, LABOV, HERZOG, 1968; LABOV, 1972, 1994, 2003). Além da definição do corpus utilizado para a coleta de dados, diversas etapas foram percorridas, da delimitação do fenômeno a ser estudado ao tratamento das ocorrências de clíticos em complexos verbais, quais sejam: (i) a definição da variável dependente; (ii) a determinação das variáveis independentes - extralinguísticas e linguísticas; (iii) o tratamento variacionista - da coleta dos dados de clíticos em complexos verbais à interpretação dos resultados. Embora em Nunes (2009) diversas variáveis tenham sido investigadas, neste artigo será focalizada somente a evolução geral das formas alternantes no decurso dos séculos em análise, controlada por meio da variável extralinguística ‘época da publicação'.

Para a investigação, elegeu-se, inicialmente, como corpus, a coletânea de textos disponíveis no site do projeto Varport (www.letras.ufrj.br/varport). Trata-se de textos produzidos em jornais - anúncios, editoriais e notícias - publicados, no Brasil e em Portugal, no decorrer dos séculos XIX e XX. O material encontra-se organizado de acordo com a segmentação de cada século consoante as seguintes fases: a) século XIX: fase 1 (1808-1840), fase 2 (1841-1870) e fase 3 (1871-1890); e b) século XX: fase 4 (1901-1924), fase 5 (1925-1949), fase 6 (19501974) e fase 7 (1975-2000).

Tendo em vista que toda a coleta dos dados do VARPORT em textos do século XX ofereceu um número de ocorrências que se julgou inadequado para uma análise quantitativa variacionista consistente (menos de 100 dados por variedade), fez-se necessária a ampliação do material a ser analisado. Outra parte do corpus foi, então, composta, seguindo os mesmos critérios adotados pelo projeto VARPORT, a partir da coleta de textos em jornais do século XX adquiridos no Real Gabinete Português e na Biblioteca Nacional do Rio de Janeiro, para a amostra brasileira, e nos arquivos da sede do Jornal Diário de Notícias, em Portugal, para a amostra europeia.

A ampliação do corpus para o século XX garantiu o aumento do número de dados, conforme se pode verificar na tabela a seguir.

Tabela 1: Distribuição geral dos dados do corpus por variedade e século

\begin{tabular}{c|c||c||c||c}
\hline \hline $\begin{array}{c}\text { Jornais } \\
\text { brasileiros - } \\
\text { Século XIX }\end{array}$ & $\begin{array}{c}\text { Jornais } \\
\text { brasileiros - } \\
\text { Século XX }\end{array}$ & $\begin{array}{c}\text { Jornais europeus } \\
\text { - Século XIX }\end{array}$ & $\begin{array}{c}\text { Jornais europeus } \\
\text {-Século XX }\end{array}$ & Total \\
\hline \hline 177 dados & 123 dados & 209 dados & 240 dados & 749 dados \\
\hline \hline
\end{tabular}

A coleta de dados resultou no total de 749 ocorrências de clíticos em construções com complexos verbais, sendo 300 nos textos brasileiros e 449 nas produções europeias. A separação dos dados brasileiros e europeus constitui opção metodológica fundamental para investigar o pressuposto eminentemente sociolinguístico de que os padrões da modalidade 
escrita brasileira se alterariam, especialmente no fim do século XIX, para atender ao modelo de escrita europeia, conforme propõe Pagotto (1998). ${ }^{2}$

\section{DISTRIBUIÇÃO DOS DADOS PELAS FORMAS ALTERNANTES}

\subsection{A colocação pronominal em complexos verbais na escrita brasileira}

Observe-se, a seguir, a distribuição, em valores absolutos e percentuais, das ocorrências de clíticos pronominais em estruturas verbais complexas nos textos brasileiros, por cada uma das variantes.

Destaque-se que não foram incluídos, nessa etapa de contagem dos dados, os contextos de início absoluto de oração, em função da sua especificidade, o que faz com que se levem em conta, a partir de agora, o total de 269 ocorrências (e não mais 300). Na realidade, o contexto inicial de oração não pode estar misturado aos demais porque registra dados categóricos; desse modo, observa-se outra configuração da regra variável na escrita, sem, por exemplo, ter sido registrada qualquer ocorrência de próclise ao complexo verbal.

Tabela 2: Distribuição das variantes em contexto de verbo não inicial nos textos brasileiros - séculos XIX e XX

TEXTOS BRASILEIROS

\begin{tabular}{|c|c|c|c|c|c|c|c|}
\hline \multicolumn{4}{|c|}{ Século XIX } & \multicolumn{4}{|c|}{ Século XX } \\
\hline cl v1 v2 & v1-cl v2 & v1 cl v2 & v1 v2 cl & clv1 v2 & v1-cl v2 & v1 cl v2 & v1 v2 cl \\
\hline $\begin{array}{c}64 \% \\
101 / 159\end{array}$ & $\begin{array}{c}7 \% \\
12 / 159\end{array}$ & $\begin{array}{c}3 \% \\
6 / 159\end{array}$ & $\begin{array}{c}26 \% \\
40 / 159\end{array}$ & $\begin{array}{c}44 \% \\
48 / 110\end{array}$ & $\begin{array}{c}4 \% \\
5 / 110\end{array}$ & $\begin{array}{c}14 \% \\
16 / 110\end{array}$ & $\begin{array}{c}38 \% \\
41 / 110\end{array}$ \\
\hline
\end{tabular}

Pode-se observar, inicialmente, a partir dos dados da Tabela 2, a grande produtividade da variante pré-complexo verbal nos dados brasileiros do século XIX. Em comparação com os dados do século XX, nota-se o decréscimo dessa variante, de $64 \%$ para $44 \%$. A título de ilustração, apresentam-se, a seguir, algumas realizações da variante cl V1 V2 do corpus brasileiro nos dois séculos sob análise.

a) Dados brasileiros - século XIX: variante cl V1 V2

(1) Quem a quizer comprar falle com José Gonçalves Oires. [E-B-81-Ja-011; anúncio - fase $1^{3}$ ]

(2) Se tal tem sido sempre o vosso pre- | mio; se ainda assim vós tudo fazeis pe- | la cauza da Nação, da Patria, da Constituição, que em Portugal se está fazen- $\mid$ do com assistencia de vossos egrégias... [E-B-81-Je-002; editorial - fase 1]

(3) As mizeras crianças não $\mid$ se podendo conter, coagidas pelas necessidades [E-B83-Je-004; editorial - fase 3]

b) Dados brasileiros - século XX: variante cl V1 V2

(4) Os effeitos da "Aspirina" legitima, em combinação | coma acção estimulante da Cafeina, produzem maravilho- | sos resultados nos casos em que se tem de combater a debi -| lidade e o esgotamento. [E-B-91-Ja-035; anúncio - fase 4]

\footnotetext{
${ }^{2}$ Sabe-se que, no aporte teórico que propõe a existência de gramáticas em competição (cf. GALVES, BRITO, PAIXÃO DE SOUSA, 2005; MARTINS, 2009), se assume por pressuposto que a escrita brasileira pode manifestar padrões tanto do que se convencionou chamar de gramática do PE quanto da suposta gramática do PB. Embora o presente artigo não se filie a essa corrente de estudos, admite-se que os resultados sociolinguísticos ora apresentados podem perfeitamente servir de subsídios à referida orientação teóricometodológica e, desse modo, não partir da segmentação dos dados em "brasileiros" e "europeus".

${ }^{3}$ As fontes dos exemplos extraídos do Corpus VARPORT estão identificadas pelo código utilizado pelo próprio projeto, acompanhado da indicação do gênero textual e do período da publicação; os exemplos advindos da ampliação do corpus recebem exclusivamente a indicação do gênero e do período.
} 
(5) Não se póde, de certo, destruir as fatalidades criadas pelas condições externas independentes de nossa vontade, ... [editorial - fase 4]

(6) Durante a operação, em que lhe foi | tirada uma parte do intestino, João Paulo | recebeu quase dois litros de sangue, por | causa da forte hemorragia. [E-B-94-Jn012; notícia - fase 7]

Quanto à realização das variantes internas ao complexo verbal, pouco expressivas em comparação com as outras variantes, é interessante observar que, no século XIX, há um número de dados levemente superior da variante enclítica a V1, aquela com hífen (7\%), em comparação com a variante considerada proclítica a V2, aquela sem hífen (3\%). No século XX, verifica-se o aumento de registros da variante V1 cl V2 (14\%), com relação aos da variante V1-cl V2 (4\%). Conferem-se, a seguir, alguns exemplos coletados no corpus:

a) Dados brasileiros - século XIX: variante V1-cl V2

(7) Cada / dia de sessão póde-se reduzir a torturas / physicas e Moraes [...] [E-B-83Jn-046; notícia - fase 3]

(8) Ourivesaria Halphen| Para evitar falsificações e usurpações de nome, deve-se exigir os dous carimbos juntos. [E-B-83-Ja-041; anúncio - fase 3]

b) Dados brasileiros - século XIX: variante V1 cl V2

(9) As | pessoas que quiserem typografias arran- | jadas com gosto, podem se dirigir á praça |da Constituição n. 64, loja de Paula Brito (...)” [E-B-82-Ja-00; anúncio - fase 2]

(10) e quando sua remor- $\mid$ denta consciencia o accusar dos incalculaveis $\mid$ males, que tem cauzado, para servir a ho- | mens, inimigos da patria de Instrumento; e | quando em fim, os pungentes gemidos de | milhares de familias clamarem aos ceos vin- | gança contra $V$. Ex. por ter lhes sacrificado | entao $V$. Ex. ficará envergonhado de haver $\mid$ feito tao bom papel... [E-B-81-Je-008; editorial - fase 1]

c) Dados brasileiros - século XX: variante V1-cl V2

(11) Você, por isso, agora não vacilará mais. Êste ano, ao invés de presentes de | duração tão fugaz, você vai-lhes oferecer algo para sempre... [E-B-93-Ja-015; anúncio - fase 6]

(12) O que ficou dito da desaggregação de certas fatalidades naturaes, pode-se egualmente applicar as fatalidades historicas. [Notícia - fase 7]

d) Dados brasileiros - século XX: V1 cl V2

(13) Os afiados dentes da corrosão geralmente começam a se formar com a | oxidação do óleo. [E-B-93-Ja-033; anúncio - fase 3]

(14) Informe-se com seu gerente. E descubra por que cada vez mais as empresas estão se interligando com o Itaú. [anúncio - fase 4]

No que se refere à variante enclítica a V2, registraram-se $26 \%$ de ocorrências nas produções do Brasil durante o século XIX e 38\% no século XX. Comparando-se os dois séculos, pode-se observar o aumento do uso da variante pós-complexo verbal. Os exemplos seguintes mostram a realização dessa variante no corpus brasileiro.

e) Dados brasileiros - século XIX: variante V1 V2-cl

(15) Os que forem moradores fóra desta cidade, como em Lisboa, Bahia, etc., pódem corresponder-se com elle pelo correio, dirigindo-lhe as suas ordens. [E-B-81-Ja-024; anúncio- fase 1]

(16) V. Ex. deve lembrar-se que estamos ao facto de | que um pretendente que outr'ora derramara seu $\mid$ sangue em defesa do THRONO pedira ao MO- | NARCHA o lugar de official archivista da secreta- | ria da Guerra... [E-B-82-Je-001; editorial - fase 2]

f) Dados brasileiros - século XX: variante V1 V2-cl 
(17) E si não | pode fazel-o, adopte o costume | de acompanhar suas refeições | a p r e s $s$ a d a s com a saborosa | Malzbier da Brahma. [E-B-92-Ja-031; anúncio - fase 5]

(18) No dia trinta deste mês deve realizar-se, em Genebra, uma nova reunião da Conferencia Internacional do Trabalho. [E-B-92-Je-004; editorial - fase 5]

Com a análise geral da distribuição dos dados entre os dois séculos na amostra brasileira, é possível destacar que a variante pré-complexo verbal apresenta relevante declínio na transição do século XIX para o XX, enquanto se dá o aumento do uso da variante pós-complexo verbal. Quanto às duas variantes internas ao complexo verbal, atesta-se sua baixa produtividade na escrita dos dois séculos e o aumento do uso da variante proclítica a V2 no século XX.

\subsection{A colocação pronominal em complexos verbais na escrita europeia}

Podem-se observar, na tabela abaixo, os valores absolutos e percentuais relativos às variantes da ordem dos clíticos pronominais - excetuando-se, também, os contextos de início absoluto de oração - na amostra europeia em produções dos séculos XIX e XX.

Tabela 3: Distribuição das variantes em contexto de verbo não inicial nos textos portugueses - séculos XIX e $\mathrm{XX}$

\begin{tabular}{|c|c|c|c|c|c|c|c|}
\hline \multicolumn{8}{|c|}{ TEXTOS EUROPEUS } \\
\hline \multicolumn{4}{|c|}{ Século XIX } & \multicolumn{4}{|c|}{ Século XX } \\
\hline cl v1 v2 & v1-cl v2 & v1 cl v2 & v1 v2 cl & cl v1 v2 & v1-cl v2 & v1 cl v2 & v1 v2 cl \\
\hline $\begin{array}{c}66 \% \\
120 / 180\end{array}$ & $\begin{array}{c}3 \% \\
5 / 180\end{array}$ & $\begin{array}{c}1 \% \\
1 / 180\end{array}$ & $\begin{array}{c}30 \% \\
54 / 180\end{array}$ & $\begin{array}{c}51 \% \\
106 / 212\end{array}$ & $\begin{array}{c}10 \% \\
23 / 212\end{array}$ & $\begin{array}{c}1 \% \\
4 / 212\end{array}$ & $\begin{array}{c}38 \% \\
79 / 212\end{array}$ \\
\hline
\end{tabular}

Na Tabela 3, observa-se que, no século XIX, a escrita jornalística europeia registra $66 \%$ de ocorrências de próclise ao complexo verbal e, no XX, 51\%. De modo geral, pode-se afirmar que as amostras brasileira e europeia, na maior parte do século XIX, apresentam comportamentos semelhantes na modalidade escrita, no sentido de que se verifica ampla preferência pela variante pré-complexo verbal e, em segundo lugar, pela variante póscomplexo verbal, o que, de certa forma, também ocorre no século XX. Esse resultado vinculase, na realidade, à forte influência do modelo europeu na escrita brasileira do fim do século XIX, influência bem descrita por Pagotto (1998).

Destacam-se, primeiramente, alguns exemplos retirados do corpus europeu que ilustram a variante pré-complexo verbal nos séculos XIX e XX.

a) Dados europeus - século XIX: variante cl V1 V2

(19) Qualquer passageiro pode tambem levar comsigo a sua bagagem, que lhe será conduzida gratis, ( E-P-82-Ja-007; anúncio - fase 2)

(20) como a historia o hade surprehender no seu domicilio da rua dos Navegantes. [E-P-83-Je-005; editorial - fase 3]

(21) Todos se devem aggregar para conseguir este resultado [E-P-83-Je-010; editorial - fase 3]

b) Dados europeus - século XX: variante cl V1 V2

(22) Hoje, que se estão multiplicando os vehiculos que nos hão de transportar no arbalão, [E-P-91-Je-001; editorial - fase 4]

(23) há que realçar as obras de arranjo urbano do largo fronteiro, onde dia e noite se tem trabalhado, dando ao recinto um aspecto diferente. [Notícia - fase 6] 
Os dados das variantes internas ao complexo verbal representam a minoria das ocorrências nos dois séculos analisados também no corpus europeu. As produções do século XX apresentam leve aumento no uso dessa variante, quase exclusivamente com hífen. Os exemplos da variante intra-complexo verbal sem hífen representam apenas $1 \%$ das amostras de cada século, o que corresponde a um dado no século XIX e quatro no século XX. Como, por hipótese, não se espera encontrar a próclise a V2, forma tipicamente brasileira, é preciso listar os contextos em que não se verifica o hífen a V1, a fim de detectar as construções em questão.

Dos dados mencionados, serão apresentados, a seguir, exemplos da variante intra-complexo verbal com hífen e a ocorrência da variante intra-complexo verbal sem hífen encontrados no século XIX. Quanto aos observados no século XX, selecionaram-se, dentre as 23 ocorrências, algumas representantes da variante intra-complexo verbal com hífen, e as quatro ocorrências da variante intra-complexo verbal sem hífen no corpus do século XX.

c) Dados europeus - século XIX: variante V1-cl V2

(24) todas as regalias do systema democratico vae-as o povo conquistando pouco a роисо [E-P-83-Je-008; editorial - fase 3]

(25) O Cambio tem-se conservado a vinte e quatro; e nem se póde claramente annunciar semelhante negocio [ E-P-81-Jn-013; notícia - fase 1]

d) Dados europeus - século XIX: variante V1 cl V2

(26) tudo emfim quanto póde dar um regimen em decomposição moral e política - $e$ nós havíamos de nos calar? [E-P-83-Je-006; editorial - fase 3]

e) Dados europeus - século XX: variante V1-cl V2

(27) Corrigem-se dentaduras defeituosas a poder-se comer com elas, quem não ficar satisfeito nada pagará. [E-P-92-Ja-005; anúncio - fase 5)

(28) A estatistica vai-se regularizando e actualizando, e avança para a desejada perfeição. [Editorial - fase 5]

(29) A referida mulher foi-lhe tambem apreendido um brinco antigo e valioso (...) [notícia - fase 6]

(30) Após a proclamação da independência unilateral do Kosovo, os sérvios têm-se manifestado diariamente, contra o novo país, tentando uma secessão e uma união à Sérvia. [Notícia - fase 7]

f) Dados europeus - século XX: variante V1 cl V2

(31) Por ter que se ausentar com urgencia de Portugal vende um rico casaco de Peles Griz de Guanaco da Australia. [Anúncio - fase 5]

(32) Que motivos levaram o Estado a decretar o fabrico e a compra dum certo numero de unidades navais, com o material e o armamento que terá de as guarnecer? [E-P-92-Je-006] [editorial - fase 5]

(33) a dispersão de um Ocidente agitado, composto de um conjunto de nações incapazes de um entendimento político na paz para evitar terem mais tarde de se unir perante as inevitáveis contingências da catástrofe. [Editorial - fase 5]

(34) Foi uma cerimónia cheia de colorido, celebrada no Parlamento de Otava, e nela participaram, além do primeiro-ministro, líderes de vários tribos índias e esquimós (inuit, como preferem se chamar). [Editorial - fase 7$]^{4}$

\footnotetext{
${ }^{4}$ Esse dado, por inusitado para a variedade europeia, necessita de esclarecimentos sobre sua autoria e, ainda, sobre o fato de que continha no contexto um fragmento, na porção anterior ao complexo verbal, ininteligível.
}

Work. Pap. Linguíst., 13(2): 85-99, Florianópolis, abr./jul, 2013 
É interessante ressaltar que os dados da variante intra-complexo verbal sem hífen apresentam comportamento semelhante nas produções dos séculos XIX e XX. Com exceção de um dado do século XX, todas as ocorrências dessa variante compõem-se da estrutura formada pelos modais "ter" e "haver" como auxiliar, acompanhados dos elementos "de" ou "que". Dessa forma, o tipo de ocorrência registrado no corpus europeu pode justificar a impossibilidade de inserção do hífen, que não se assemelha ao que ocorre no corpus brasileiro, em que se dá, de fato, a variante $\mathrm{v} 1 \mathrm{cl}$ v2, sem interferência de qualquer elemento interveniente. Em outras palavras, assume-se, aqui, que não se trata efetivamente da mesma variante; enquanto ocorre a legítima próclise a V2 nos dados brasileiros, o mesmo não se pode afirmar da amostra europeia.

Registraram-se, no corpus do século XIX, 30\% de ocorrências de ênclise ao complexo verbal e, no século XX, 38\%. Dessa forma, nota-se que os dados da variante pós-complexo verbal se apresentam em distribuição equilibrada considerando os dois séculos em questão. Ressalte-se, ainda, que a porcentagem dos dados enclíticos ao complexo verbal na variedade europeia se assemelha ao número de ocorrências no corpus brasileiro, nos dois séculos analisados, o que sugere que a modalidade escrita estabelece uma aproximação entre as normas brasileiras e europeias nesse contexto. Destacam-se alguns exemplos da variante V1 V2-cl coletados no corpus europeu, a saber:

g) Dados europeus - século XIX: variante V1 V2-cl

(35) Os pretendentes podem dirigir-se ao seu escriptorio na rua da Emenda $n .^{\circ} 16$. [EP-81-Ja-004; anúncio - fase 1]

(36) N'este systema política póde desenvolver-se e aperfeiçoar-se a parte material da vida cívica [E-P-83-Je-008; editorial - fase 3]

h) Dados europeus - século XX: variante V1 V2-cl

(37) Para os clientes de fora de Lisboa podem preparar-se aplicações a fim de serem aplicadas nas suas casas. [Anúncio - fase 4]

(38) O seu estudo revela uma crise profunda, mas felizmente bastantes sintomas de melhoria começam a acentuar-se (...) [editorial - fase 2]

Da distribuição dos dados da amostra europeia, destaca-se a baixa produtividade das variantes internas ao complexo verbal, com ou sem hífen, nos dois séculos em questão. Além disso, cabe ressaltar a diminuição do uso da variante pré-complexo verbal do século XIX para o XX. Os dados da variante pós-complexo verbal mantiveram-se equilibrados na amostra ao longo dos dois séculos analisados.

\section{A TRAJETÓRIA DA ORDEM DOS CLÍTICOS}

A distribuição dos dados pela variável 'época da publicação' permitiu exibir o padrão de colocação pronominal em complexos verbais em cada período controlado. Como os dados das variantes intra-complexo verbal se mostraram incipientes para a representação percentual, apresenta-se, a seguir, a distribuição das ocorrências por fase, contabilizando as ocorrências antes, depois e no meio ${ }^{5}$ do complexo verbal.

\footnotetext{
${ }^{5}$ Sem dúvida, o controle dos dados de clíticos entre as duas formas verbais deve ser feito sempre considerando separadamente a ênclise a V1 e a próclise a V2, como se apresentou nas Tabelas 1 e 2 deste artigo. Por limitação do trabalho que deu origem a este artigo (NUNES, 2009), que inadequadamente não fez essa separação, não foi possível evitar a reprodução desses dados em conjunto, mas, na análise das ocorrências e nas considerações sobre a trajetória da ordem do clítico, sempre se explicita o comportamento diferenciado das referidas estruturas. 


\subsection{A variável extralinguística ‘época da publicação’ nos dados brasileiros}

Observem-se a seguir os resultados no padrão gráfico, que expõe os períodos controlados para os séculos XIX e XX num contínuo representado pelas sete fases:

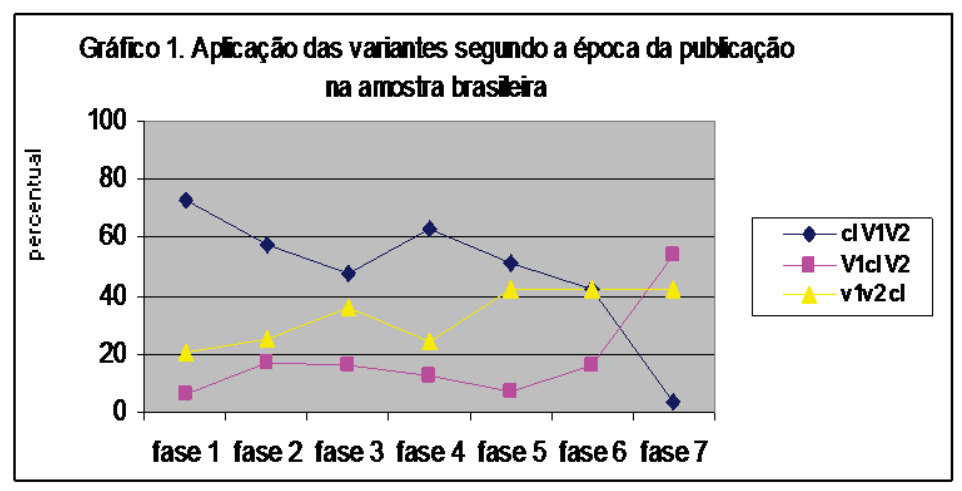

No que diz respeito à distribuição dos dados durante o século XIX (até a fase 3), observa-se forte tendência ao uso da variante pré-complexo verbal nas duas primeiras fases, respectivamente em $73 \%$ e $58 \%$ dos dados, enquanto a terceira apresenta uma queda da variante, registrada em $48 \%$ dos dados. Assim, no correr das três primeiras fases, ocorre a diminuição gradativa do uso da variante cl V1 V2. Por outro lado, as variantes internas ao complexo verbal apresentam índice de crescimento, figurando em apenas $6 \%$ dos dados no início do século XIX e em torno de $17 \%$ nos dados das fases 2 e 3 . No geral, a variante póscomplexo verbal apresenta elevação de uso ao longo das três primeiras fases, mantendo-se estável.

Vale destacar o fato de que, na última fase do século XIX (fase 3), os padrões de colocação pronominal se apresentam bem diferentes daqueles observados no início do século XX (fase 4). Essa diferença, especialmente no que se refere ao aumento da variante pré-complexo verbal na transição entre os séculos em questão, pode fortalecer a tese de que a passagem dos séculos XIX para o XX representa, na sociedade brasileira, a reprodução do padrão europeu na escrita, tido como modelo de correção da Língua Portuguesa (cf. PAGOTTO, 1998). Devido a fatores histórico-sociais, como a vinda e instalação da corte real portuguesa no Rio de Janeiro e o processo de relusitanização da cidade, de maneira lenta e gradual, verificam-se, nas últimas décadas do século XIX e primeiras do XX, as principais manifestações de um padrão escrito em consonância com o modelo europeu.

Ao que parece, no decorrer do século XX, essa tendência homogeneizante entre a escrita brasileira e portuguesa perde força. A imprensa do Brasil dá pistas de que revelaria, especialmente a partir da fase 5, período pós-Semana de Arte Moderna, um processo de aproximação, ainda que inconsciente, à norma objetiva da fala brasileira. A última fase do século XX surpreende por apresentar apenas um dado da variante pré-complexo verbal. A maioria dos dados figura em posição intra-CV (54\%) ou pós-CV (42\%).

Em linhas gerais, a observação dos exemplos das variantes internas ao complexo permite afirmar que aumenta, com o passar do tempo, a variante proclítica a V2 e diminui a proclítica a V1, independentemente do contexto anterior. Desse modo, os elementos tradicionalmente considerados atratores do clítico vão exercendo, ao que tudo indica, cada vez menos o efeito proclisador nos dados da amostra brasileira.

Destacam-se, aqui, dados das variantes internas ao complexo verbal na primeira fase tanto do século XIX quanto do XX, para a observação do contexto linguístico em que se verifica tal 
colocação. Embora os exemplos evidenciem a ligação do clítico a V1, também se encontram dados de próclise a V2 mesmo na presença de elementos proclisadores no contexto antecedente ao complexo.

\section{V1-cl V2 / V1 cl V2 (Amostra brasileira)}

(39) Joaquim José Pereira noticia saber cura Herneas no escroto com toda a perfeição sem que fique defeituoso, nem passe pelo menor risco de vida o que dellas se curar, como tem se verificado por este continente: toda pessoa, que se quizer se servir do seu prestimo, o pode procurar na Rua dos Ferrasores na casa número 175. [E-B-81-Ja-026; anúncio - fase 1]

(40) Esta nação, tendo á frente hum Rei, cuja firmeza de sentimentos he sómente igualada pela sua honra, tem-se exposto aos maiores perigos [E-B-81-Jn-012, notícia - fase 1]

\section{V1-cl V2 / V1 cl V2 (Amostra brasileira)}

(41) Os doentes podem se tratar com os medicos de sua confiança. [E-B-91-Ja-029; anúncio - fase 4]

(42) O que ficou dito da desaggregação de certas fatalidades naturaes, pode-se egualmente applicar as fatalidades historicas. [Editorial - fase 4]

(43) Por meio de missões, conferencias, frequentemente realizadas [ilegível] gratuita e profusamente distribuidos, deve-se pregar a verdade ... [editorial - fase 4]

Apresentam-se, ainda, ocorrências da variante pré-complexo verbal coletadas nas últimas décadas dos séculos XIX e XX, para a observação dos contextos de sua ocorrência.

\section{cl V1 V2 (Amostra brasileira)}

(44) Existem muitas imitações. Para évital-as, não se devem aceitar senão os frascos que levam sobre o involucro exterior a assignatura de Raquin e o selo official (em azul) do governo francez. [E-B-83-Ja-059; anúncio - fase 3]

(45) As mizeras crianças não | se podendo conter, coagidas pelas necessidades [E-B83-Je-004; editorial - fase 3]

(46) pelo valiosisimo | concurso que nos estão generosamente pres- | tando di [ns] companheiros de officina, o aug | mento do numero [E-B-83-Je-005; editorial - fase 3]

(47) Cobre-se de / uma rica vegetação. Plantam-se cereaes, / porém, lá um bom dia, voltam as aguas / por onde se tinham escoado, e o lago com / ruido espantoso se enche novamente. [E-B-83-Jn-036; notícia - fase 3]

\section{cl V1 V2 (Amostra brasileira)}

(48) Durante a operação, em que lhe foi $\mid$ tirada uma parte do intestino, João Paulo | recebeu quase dois litros de sangue, por | causa da forte hemorragia. [E-B-94-Jn012; notícia - fase 7]

Os dados acima permitem observar que a variante pré-CV, que se encontra em variados contextos com a presença de tradicional elemento proclisador no fim do século XIX, ocorre apenas uma vez no fim do século XX e apenas em uma construção específica de voz passiva.

\subsection{A variável extralinguística 'época da publicação' nos dados europeus}

Observe-se a representação gráfica da colocação pronominal nas sete fases, a seguir: 


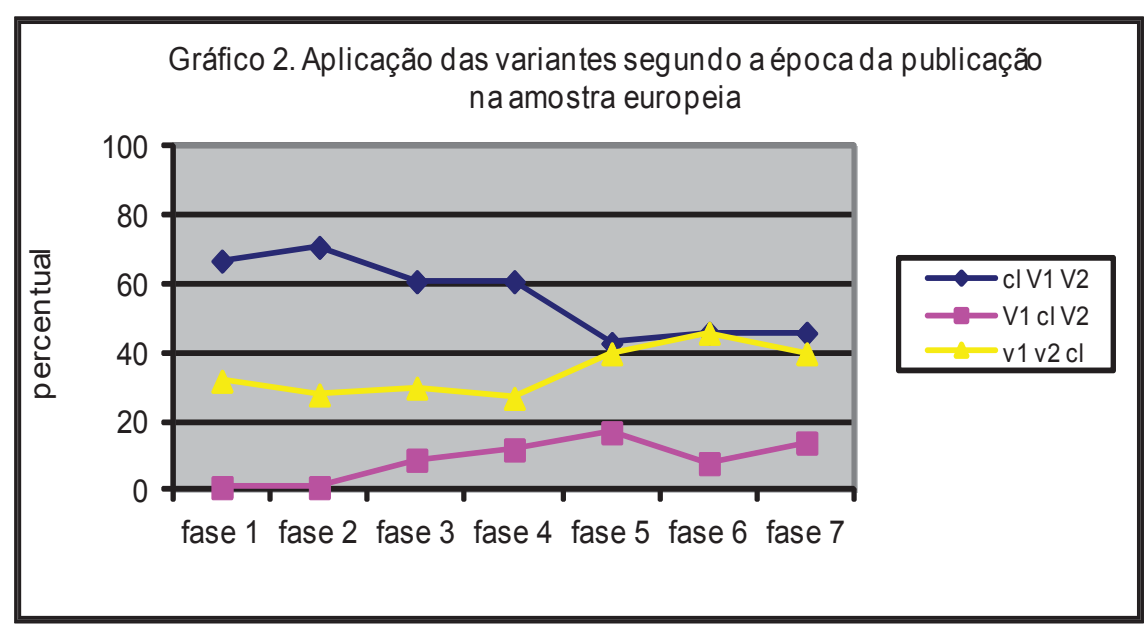

Os dados do século XIX coletados no corpus europeu revelam comportamento aproximado quanto à preferência da posição do clítico ao longo das três fases iniciais, já que os percentuais de cada variante analisada se mantêm estáveis, com valores bem semelhantes. Conforme já se observou, pode-se conferir o uso mais produtivo da variante pré-complexo verbal, no século XIX, figurando em mais da metade dos casos no decorrer das décadas. Por outro lado, os dados da variante intra-complexo verbal ocupam o outro extremo, configurando a minoria das ocorrências, entre 1 e $9 \%$ dos casos, o que corresponde a um dado da variante nas duas primeiras fases e quatro ocorrências na fase 3 .

Com exceção da primeira fase do século XX (fase 4), que demonstra tendência ao uso preferencial pela variante pré-complexo verbal (61\%), as demais fases apresentam dados em distribuição equilibrada entre as variantes pré e pós-complexo verbal, que figuram entre 40 e $46 \%$ em cada uma das três fases finais. Ao que parece, comparando-se os dois séculos, os dados europeus passam a admitir, no contexto de complexos verbais antecedidos de algum elemento, maior variabilidade entre as posições pré-CV e pós-CV, o que pode estar correlacionado à atenuação do efeito proclisador de algumas partículas. Apenas uma análise detalhadas dos elementos anteriores ao complexo verbal poderá aferir a validade da hipótese.

Da mesma sorte que no século XIX, os dados da variante intra-complexo verbal no século XX continuam compondo a menor parte da amostra, estruturas estas que podem ser analisadas a partir de exemplos extraídos do corpus:

\section{V1-cl V2 / V1 cl V2 (Amostra europeia)}

\section{Fase 4}

(49) ou nos que asseguram na praia escolhida a acção sedativa ou excitante do grande mar e dos vapores salinos que se evolvem das suas ondas, batidas pelos ventos e pelos temporaes que as levantam em serras de agua; mas, deve-se necessariamente attender a alguma cousa mais. Esse outro factor, é a salubridade da região. [E-P-91Je-001; editorial - fase 4]

(50) Como é de calcular, a falta das hortaliças está-se tornando cada vez mais sensivel, porquanto elas constituem um dos alimentos mais indispensáveis à população da capital. (Notícia - fase 4)

(51) para este fim será apresentada, a fim de mais facilmente poder-se concluir a discussão do referido projecto (...) [notícia - fase 4] 


\section{Fase 5}

(52) Não há necessidade de sofrer mais tempo porque agora pode-se ver livre da sua dor com um simples Emplastro Poroso Allcock. [anúncio - fase 5]

(53) A estatistica vai-se regularizando e actualizando, e avança para a desejada perfeição. [Editorial - fase 5]

(54) Um tribunal de Paris está-se ocupando de um caso bicudo. [Notícia - fase 5]

\section{Fase 6}

(55) De facto, a forma foi-se degradando e deteriorando (...) [editorial - fase 6]

(56) A referida mulher foi-lhe tambem apreendido um brinco antigo e valioso (...) [notícia - fase 6]

(57) A posse foi-lhe conferida pelo comandante distrital da L. P. de Setúbal. [Notícia - fase 6]

\section{Fase 7}

(58) Mas vão-se cansando de tantas vezes terem de correr o grande risco. [E-P-94-Je002; editorial - fase 4]

(59) São eles que dão vida e alma histórica às cidades no que isso representa de apelo turístico. E de vivacidade económica. Em Portugal isso tem-se negligenciado. [Editorial - fase 7]

(60) Foi uma cerimónia cheia de colorido, celebrada no Parlamento de Otava, e nela participaram, além do primeiro-ministro, líderes de vários tribos índias e esquimós (inuit, como preferem se chamar). [Editorial - fase 7]

(61) Após a proclamação da independência unilateral do Kosovo, os sérvios têm-se manifestado diariamente, contra o novo país, tentando uma secessão e uma união à Sérvia. [Notícia - fase 7

Os exemplos confirmam a tendência europeia à variante enclítica a V1 em contextos em que não se observa a presença de elementos considerados tradicionalmente proclisadores. A única ocorrência de clítico sem hífen ("como preferem se chamar"), que nunca foi apontada como uma construção europeia, está por ser esclarecida. Por hipótese, ela pode resultar, por exemplo, da interferência de um escritor brasileiro no texto português, tendo em vista estar totalmente fora dos padrões europeus, em que apenas os complexos verbais com elementos internos do tipo "ter que / de" costumam admitir o clítico adjacente a V2, sem hífen.

Por ora, não se pode assegurar que os resultados da variável 'época da publicação' sinalizem relevantes alterações no comportamento linguístico da colocação pronominal nos dados europeus ao longo dos séculos XIX e XX. Ao que tudo indica, variáveis linguísticas podem ser responsáveis pelas diferenças nos índices percentuais, o que necessita de investigação particular.

\section{CONSIDERAÇÕES FINAIS}

A análise diacrônica da colocação pronominal em complexos verbais mostra que a modalidade escrita - especialmente no século XIX, em que é evidente a normatização da escrita brasileira segundo os padrões lusitanos (PAGOTTO, 1998; FARACO, 2008) - oculta as conhecidas e fortes diferenças entre as normas vernaculares do $\mathrm{PB}$ e do $\mathrm{PE}$ quanto à colocação pronominal. No entanto, apesar das referidas semelhanças nas amostras brasileiras e europeias, o estudo revela, ao longo do período investigado, diferentes trajetórias do fenômeno. 
Enquanto, especialmente no século XIX, tanto o padrão brasileiro quanto o padrão europeu eram o da colocação proclítica ao complexo verbal em contextos de verbo não inicial, possivelmente preferida em contextos com elementos proclisadores, a amostra brasileira, no decorrer do século XX, passa a apresentar com maior frequência, em mais da metade dos dados, a variante interna ao complexo verbal - em sua maioria, do tipo próclise a V2. Em contrapartida, nos dados da amostra europeia, a variante interna ao complexo verbal, do tipo ênclise a V1, é a menos produtiva, nos dois séculos em questão; nos textos do século XX, ocorre uma distribuição equilibrada entre as variantes proclítica e enclítica ao complexo verbal, o que, por hipótese, obedece a restrições de natureza fundamentalmente estrutural, como tipo de elemento proclisador, tipo de clítico e tipo de complexo.

Ao que tudo indica, nos textos europeus, as eventuais alterações no padrão de colocação pronominal não parecem estar vinculadas a aspectos extralinguísticos como a época da publicação; antes, podem encontrar fundamento nos contextos linguísticos que envolvem a realização de cada variante. Nos dados brasileiros, o fator diacrônico demonstra um quadro que sugere início da mudança na escrita padrão, apenas sutilmente sinalizado nos dados do século XIX. No século XX, destaque-se, além do declínio no uso da variante pré-CV, a consequente elevação das demais variantes especialmente na última fase, em que se dá a alteração de comportamento de forma evidente. Dessa forma, se seguirem o curso do padrão ora verificado, as fases iniciais do século XXI registrarão na escrita mais fortemente as inovações acerca da colocação pronominal no PB vernacular, com a implementação cada vez mais intensa da próclise a V2 nos textos jornalísticos. Resta aguardar e analisar, considerando-se sempre as motivações sociais e linguísticas - estas últimas não contempladas no escopo do presente trabalho -, novas ocorrências de clíticos em complexos verbais em textos jornalísticos.

Além da sistematização das tendências da ordem dos clíticos pronominais em complexos verbais ao longo dos séculos XIX e XX, o presente artigo permite, por fim, refletir brevemente sobre o que os dados da escrita podem revelar acerca da mudança linguística em largos períodos de tempo. Seguramente, eles podem indicar as tradições preferenciais que os jornais de circulação endereçados a camadas sociais de prestígio socioeconômico - fontes normalmente sinalizadoras da norma de comportamento social - adotavam ou adotam. Nesse sentido, a escrita é reveladora das normas ou da evolução das normas linguísticas em questão, vistas como modelos para o "bem escrever".

Além de revelarem tais normas, os resultados podem, ainda, sinalizar os comportamentos que se praticariam na fala espontânea do período em análise. Nesse sentido, independentemente do número de dados encontrados, a presença de uma estrutura que só se efetiva em uma das amostras (como é o caso da próclise a V2, que ocorre (praticamente) em apenas uma das amostras estudadas) pode indicar fortemente uma diferença gramatical entre variedades linguísticas. Ademais, curvas diferenciadas na evolução do fenômeno, como as que se detectaram nas amostras brasileira e europeia, especialmente no século XX, são reveladoras de mudanças estruturais em direções distintas no caso da colocação pronominal.

De todo o exposto, espera-se que os resultados do presente artigo possam ter contribuído não só para o conhecimento do fenômeno nas variedades brasileira e europeia do Português, mas também para o detalhamento da ordem em construções com complexos verbais que se encaixam nos padrões gerais da mudança dos modelos praticados na escrita, os quais, por sua vez, constituem, em algumas estruturas, reflexos das mudanças já há muito efetivadas na fala. 


\section{REFERÊNCIAS}

CARNEIRO, Z. O. N. Cartas Brasileiras (1808-1904): um estudo linguístico-filológico. Tese (Doutorado) - Instituto de Estudos da Linguagem, Universidade Estadual de Campinas, Campinas, SP, 2005.

CASSIMIRO, D. O. S. Análise diacrônica da colocação pronominal nas variedades brasileira e europeia do português literário: um estudo segundo o conjugado "Variação-Mudança \& Cliticização”. Dissertação (Mestrado em Letras Vernáculas) - Faculdade de Letras, Universidade Federal do Rio de Janeiro, Rio de Janeiro, 2010.

CORRÊA, C. M. M. L. Cliticização pronominal na região metropolitana do Rio de Janeiro: a interface sintaxe-fonologia. Dissertação (Mestrado em Letras Vernáculas) - Faculdade de Letras, Universidade Federal do Rio de Janeiro, Rio de Janeiro, 2012.

; VIEIRA, S. R. A ordem dos clíticos em complexos verbais na sincronia atual: uma regra variável? Signum Português brasileiro: estudos sincrônicos e diacrônicos. Londrina: UEL, v. 15, n. 1, p. 357-380, 2012.

CYRINO, S. M. L. Observações sobre a mudança diacrônica no Português do Brasil: objeto nulo e clíticos. In: ROBERTS, I.; KATO, M. (org.) Português brasileiro: uma viagem diacrônica. Campinas: Editora da Unicamp, 1996. p.163-184.

FARACO, C. A. Norma culta brasileira - desatando alguns nós. São Paulo: Parábola Editorial, 2008.

GALVES, C. M. C.; BRITTO, H. S.; PAIXÃO DE SOUSA, M. C. The Change in clitic placement from Classical to Modern European Portuguese: Results from the Tycho Brahe Corpus. Journal of Portuguese Linguistics, v. 4, p. 39-67, 2005.

KLAVANS, J. L. The independence of Syntax and Phonology in cliticization. Language 61(1), p. 95-120, 1985.

LABOV, W. Sociolinguistics patterns. Oxford: Blackwell, 1972.

. Principles of linguistic change. Oxford, Cambridge: Blackwell, 1994.

Some sociolinguistic principles. In: PAULSTON, C. B.; TUCKER, G. R. (eds.)

Sociolinguistics: the essential readings. Oxford: Blackwell, 2003. p. 235-50.

LOBO, T. A colocação dos clíticos em Português: duas sincronias em confronto. Dissertação (Mestrado) - Faculdade de Letras, Universidade de Lisboa, Lisboa, 1992.

Para uma sociolinguística histórica do Português do Brasil: edição filológica e análise linguística de cartas particulares do recôncavo da Bahia, século XIX. Tese (Doutorado em Filologia e Língua Portuguesa) - Faculdade de Filosofia, Letras e Ciências Humanas, Universidade de São Paulo, São Paulo, 2001.

MARTINS, A. M. Clíticos na história do Português. Tese (Doutorado) - Faculdade de Letras, Universidade de Lisboa, Lisboa, 1994.

MARTINS, M. A. Competição de gramáticas do português na escrita catarinense dos séculos 19 e 20. Tese (Doutorado em Linguística) - Faculdade de Letras, Universidade Federal de Santa Catarina, Florianópolis, 2009.

MORITO MACHADO, A. C. O uso e a ordem dos clíticos na escrita escolar. Dissertação (Mestrado em Letras Vernáculas) - Faculdade de Letras, Universidade Federal do Rio de Janeiro, Rio de Janeiro, 2006. 
NUNES, C. da S. Um estudo sociolingüístico sobre a ordem dos clíticos em complexos verbais no PB e no PE. Dissertação (Mestrado em Letras Vernáculas) - Faculdade de Letras, Universidade Federal do Rio de Janeiro, Rio de Janeiro, 2009.

PAGotTo, E. G. A posição dos clíticos em Português: um estudo diacrônico. Dissertação (Mestrado), UNICAMP, Campinas/SP, 1992.

49-68, 1998.

. Norma e condescendência; ciência e pureza. Línguas e instrumentos lingüísticos 2, p.

PEREIRA, M. G. D. A variação na colocação dos pronomes átonos no Português do Brasil. Dissertação (Mestrado) - Faculdade de Letras, Pontifícia Universidade Católica, Rio de Janeiro, 1981.

PETERSON, M. S.; VIEIRA, S. R. A ordem dos clíticos pronominais em complexos verbais: as normas de uso em cartas de leitor. Fórum lingüístico. Florianópolis/ SC: UFSC; vol. 9, n. 1, p.57-67, 2012.

RODRIGUES-COELHO, A. L.; VIEIRA, S. R. Variação estilística na escrita escolar monitorada: o caso da colocação pronominal. Revista do GELNE. Natal/RN, vol. 14, $\mathrm{n}^{\circ}$ especial, p. 213-238, 2012.

SCHEI, A. A colocação pronominal do português brasileiro: a língua literária contemporânea. São Paulo: Humanitas FFLCH/USP, 2003.

VIEIRA, M. de F. A cliticização pronominal em lexias verbais simples e em complexos verbais no Português Europeu oral contemporâneo: uma investigação sociolinguística. Dissertação (Mestrado em Letras Vernáculas) - Faculdade de Letras, Universidade Federal do Rio de Janeiro, Rio de Janeiro, 2011.

VIEIRA, S. R. Colocação pronominal nas variedades européia, brasileira e moçambicana: para a definição da natureza do clítico em Português. Tese (Doutorado em Letras Vernáculas) - Faculdade de Letras, Universidade Federal do Rio de Janeiro, Rio de Janeiro, 2002.

A complexidade do tratamento variacionista da ordem dos clíticos em complexos verbais. In: BERLINCK, R. de A.; HATTNHER, M. M. D.; IAGALLO, P. O. Estudos lingüísticos: níveis de análise. Araraquara; FCL-UNESP Laboratório Editorial; São Paulo: Cultura Acadêmica. 2012. p. 57-86. (Série Trilhas lingüísticas; 21)

WEINREICH, U.; LABOV, W.; HERZOG, M. Empirical foundations for theory of linguistic change. In: LEHMANN, W.; MALKIEL, Y. (eds.) Directions for historical linguistics. Austin: University of Texas Press, 1968. p. 97-195.

Recebido: $17 / 06 / 2013$

Aceito: $31 / 08 / 2013$ 